\title{
A PEDAGOGIA DA ESCUTA: APROXIMAÇÕES ENTRE INTERCULTURALIDADE E INOVAÇÃO PEDAGÓGICA
}

\author{
PEDAGOGÍA DE LA ESCUCHA: APROXIMACIONES ENTRE \\ INTERCULTURALIDAD E INNOVACIÓN PEDAGÓGICA
}

\author{
THE PEDAGOGY OF LISTENING: INTERFACES BETWEEN \\ INTERCULTURALISM AND PEDAGOGICAL INNOVATION
}

\author{
Paula Maria Aristides de Oliveira MOLINARI ${ }^{1}$
}

RESUMO: Partindo do desafio de pensar a interculturalidade e a inovação pedagógica de modo a colaborar com um grupo de pesquisa em educação, o Observatório Internacional de Inclusão, Interculturalidade e Inovação Pedagógica (OIIIIPe), com o aporte da educação musical, da performance musical e da criação artística, este artigo tem como objetivo geral descrever o plano conceitual que norteou o planejamento das ações a serem desenvolvidas num curso de formação de professores. Tratando-se de contribuir desde a arte como grande área e a música como subárea para a educação, cabe sublinhar que a interdisciplinaridade inerente ao processo é em si uma situação instigadora dos elementos mais básicos da construção de saberes para o êxito da compreensão e, portanto, da comunicação efetiva. As pedagogias musicais ativas serviram de referencial e a metodologia aplicada para mostrar os resultados e a pesquisa educacional baseada em arte, ou a ArTografia. É um dossiê que partilha resultados parciais de uma ação em curso e que envolve estudantes, graduados, docentes pesquisadores e pós-graduandos de duas universidades: uma brasileira e uma argentina. As primeiras reflexões sobre esses resultados parciais acusaram a redescoberta da sensibilização da escuta e das percepções de mundo como saberes integradores.

PALAVRAS-CHAVE: Educação musical. Educação. Escuta. Pedagogia WolfsohnMolinari. Inovação.

RESUMEN: Partiendo del desafio en pensar la interculturalidad y la innovación pedagógica con el fin de colaborar con un grupo de investigación en educación, el Observatorio Internacional de Inclusión, Interculturalidad e Innovación Pedagógica (OIIIIPe), con el aporte de la educación musical, de la performance musical y de la creación artística, el artículo tiene como objetivo general describir el plan conceptual que orientó la planificación de las acciones a desarrollar en un curso de formación de profesores. Contribuyendo desde la arte como una gran área y la música como una subárea para la educación, cabe subrayar que la interdisciplinariedad inherente al

\footnotetext{
${ }^{1}$ Universidade Federal do Maranhão (UFMA), São Luís - MA - Brasil. Docente do Curso de Linguagens e Códigos/Música - Campus São Bernardo. Professora orientadora colaboradora na Universidad Nacional de Rosario/Argentina, no Doutorado em Humanidades e Artes com Ênfase em Ciências da Educação. PósDoutoranda na Universidade Estadual Paulista (Unesp) - Instituto de Artes - Programa de Pós-Graduação em Música. Doutora em Comunicação e Semiótica pela Pontifícia Universidade Católica de São Paulo (PUCSP). ORCID: <https://orcid.org/0000-0001-6364-0521>.E-mail: paulamolinari@ufpi.edu.br
}

RIAEE - Revista Ibero-Americana de Estudos em Educação, Araraquara, v. 13. n. esp. 2, p. 1436-1448, set., 2018. ISSN: $1982-5587$. 
proceso es en sí una situación instigadora de los componentes más básicos de la construcción del saberes para lo éxito de la comprensión y, por lo tanto, de la comunicación efectiva. Las pedagogías musicales activas serviron como referencial y la metodología aplicada para mostrar los resultados es la investigación educacional basada en el arte, o la ArTografía. Es un dosier que comparte los resultados parciales de una acción en curso y que implica estudiantes, graduados, docentes pesquisa dores y estudiantes de posgrado de dos universidades: una brasileña y una argentina. Las primeras reflexiones sobre estos resultados parciales mostraron lo redescubrimiento de la sensibilización de la escucha y de las percepciones del mundo como saberes integradores.

PALABRAS CLAVE: Educación musical. Educación. Escucha. Pedagogía Wolfsohn Molinari. Innovación.

ABSTRACT: Taking on the challenge of reflecting on interculturalism and pedagogical innovation as a starting point to collaborate with an educational research group called The International Observatory on Inclusion, Interculturalism and Pedagogical Innovation (OIIIIPe) with the support of music education, music performance and artistic creation, this paper has the general objective of describing the conceptual plan that guided the planning of actions to be developed in a teacher training course. Having art as a major field and music as a subfield that contribute to education, one should highlight that the interdisciplinarity inherent to the process is, in itself, a situation that brings forth the most basic elements of knowledge building for a successful understanding and, therefore, also for an effective communication. Active music pedagogies were used as a framework and the methodology applied to achieve the results was arts-based educational research, or ArTography. This is a dossier that reports partial results of an ongoing action involving students, graduates, teachers, researchers, and post-graduate students from two universities: one in Brazil and the other one in Argentina. The first reflections on these partial results reveal a rediscovery of the sensitization of listening and perceptions of the world as integrating knowledge.

KEYWORDS: Music education. Education. Listening. Wolfsohn-Molinari Pedagogy. Innovation.

\section{Introdução}

Quando se fala em Educação Musical, Performance Musical ou Criação Artística, na maioria das vezes surgem na mente memórias de atividades relacionadas ao campo do entretenimento ou, quando relacionadas à Educação, em geral, estão ligadas aos eventos culturais. Vale ressaltar que tais participações em eventos são importantes porque demarcam a estrutura de tais eventos, a exemplo da abertura, dos intervalos ou dos encerramentos. Por exemplo, num congresso é comum a abertura conter uma apresentação artística que, de fato, contribui, faz parte do evento, mas não é parte do tema principal, ainda que minimamente tenha alguma relação com ele. Nesse caso, seria a abertura um 
hábito instituído nos eventos. Trata-se de uma ação que é parte do ritual que envolve os eventos acadêmicos.

Na qualidade de professores da área de Educação Musical, na universidade, somos continuamente procurados para brindar alguma de nossas atividades durante os eventos das mais diversas áreas do conhecimento. Em geral, pouca distinção há entre o que fazemos como educadores musicais, músicos performáticos ou, ainda, sobre o que nos propomos a estudar. Via de regra, não nos é perguntado quanto ao que fazemos, se nossos focos estão dirigidos a recriações, criações inéditas ou qualquer outra forma de expressão artística. Parece que basta conter a informação - musical ou artística - que tudo já se autovalida como parte do que se espera para o entretenimento.

Tal situação não é tão diferente na visão fora do ambiente acadêmico. Em geral, nossos estudantes de primeiro semestre não têm muita certeza do que, de fato, vêm fazer numa formação em Educação Musical, ou, ainda, que uma licenciatura que envolve o fazer musical é, em sua gênese, Educação Musical. Muitos buscam um contato maior com a música e a profissionalização em um instrumento, voz, composição ou, ainda, regência. Parece que qualquer formação superior que envolve música - senso comum necessariamente contempla o estudo sistemático de ao menos um instrumento, isso quando não se exige - também senso comum - a formação em vários instrumentos. De fato, isso não é verdadeiro.

Tais situações foram motivadoras para o planejamento de ações em cursos de formação de professores em que o objetivo nasceu da necessidade de construir um lugar comum entre um dos objetos de estudo da música, o que se desenvolve numa licenciatura em música e o quanto isso tem relação com outras licenciaturas, independentemente da especificidade de cada uma.

Para tal, algumas premissas foram estabelecidas. A afinidade com as pedagogias ativas definiu que tipo de abordagem estabelecer e os estudos interculturais trouxeram o aporte necessário para o estabelecimento de condutas para uma maior tolerância das diferenças e, como ação decorrente, a inovação pedagógica.

Todas as escolhas apontaram para a necessidade de falar sobre o processo durante o desenvolvimento, tornando, paralelamente, cada etapa um estudo em profundidade em que o processo é tão importante quanto o resultado. Portanto, nosso objetivo é descrever o plano conceitual que norteou o planejamento das ações a serem desenvolvidas.

RIAEE - Revista Ibero-Americana de Estudos em Educação, Araraquara, v. 13. n. esp. 2, p. 1436-1448, set., 2018. ISSN: 1982-5587. 
Dividiremos a explanação do plano conceitual em tópicos. Começaremos com a escuta, seguiremos com interculturalidade e, finalmente, inovação pedagógica.

\section{Escuta e interculturalidade}

Já mencionamos em outros estudos sobre formação pedagógica que escutar abre os olhos, os sentidos, as sensações e possibilita àquele que apreende uma voz ir mais profundamente na busca da origem de toda a expressão humana (MOLINARI, 2008, 2013). Afirmar isso é um exercício de tornar visível o quanto priorizar a escuta pode nos auxiliar a aprender e apreender melhor qualquer aspecto de que tenhamos necessidade de aproximação.

Os mecanismos da escuta não são, como costumam parecer, uma ação já dominada por todos. O exercício da escuta é um exercício, também, intelectual.

É possível, na língua portuguesa, estabelecer a distinção entre ouvir e escutar. Ouvir está ligado ao sentido da audição, enquanto escutar está relacionado à apreensão do que se ouve. Não é necessário nenhum esforço para encontrar alguma referência sobre o tema, inclusive em educação. Numa rápida consulta, usando um site de busca, é possível descobrir afirmações como a que segue:

Para quem deseja ir bem nos estudos, progredir profissionalmente, escutar é a melhor opção e haverá necessidade de prática. Nos dias de globalização, competição acirrada, as pessoas pouco escutam e desejam mais falar do que ouvir. No entanto, saber ouvir é um sábio conselho milenar que requer treinamento. Uma comunicação perfeita e sem ruídos requer atenção e bons ouvintes antes de qualquer coisa (SITE EDUCAÇÃO CC, 2018)

A referência indica, claramente, a importância e aponta a necessidade de prática, e é sobre esta, possivelmente entre tantas outras, de que tratamos aqui.

Falamos de uma escuta que se transporta ao outro, que busca o outro com uma entrega de sentidos sincera e desarmada. Para isso, Lotman (1978; 1996) e Lotman e Uspenskii (1981) podem nos dar suporte quando tratam dos diversos sistemas semióticos e afirmam que estes não se definem de maneira inequívoca, mas que o conceito de cultura está indissoluvelmente ligado às semioses.

Concebendo a escuta nessa perspectiva, como dissemos antes e damos ênfase aqui, tanto o educador quanto outros profissionais podem melhorar muito sua conduta profissional, ao incluírem um exercício de escuta como o que propomos, tocando todas as 
possibilidades de significação que não estão ditas, tomando-se, portanto, o entimema como um universo a ser considerado.

O entimema é aquela parte não vocalizada do discurso. É aquele que apreendemos sem tê-lo, de fato, recebido por meio das palavras do discurso, mas, apesar disso, está contido no discurso e (que) sem ele não se pode inferir a real significação. Sem a apreensão do entimema seria impossível levarmos em conta a dinâmica cultural de cada língua. O entimema é apreendido pelo ritmo com que se diz, da acentuação da frase (acentuação rítmica e células rítmicas variadas), da ênfase - não acento tônico - em uma sílaba ou numa palavra específica e em determinado contexto (prolongamentos expressivos e dinâmicas). Se tomarmos todas essas características, o resultado é, também, música. Ilustramos no Gráfico 1 os elementos constitutivos do entimema sem, no entanto, a intenção de representar quantitativamente a porção de cada um em discursos distintos, e, sim, de apontar que a dinâmica de todos os elementos é constitutiva do entimema.

Para os músicos mais ortodoxos, talvez os elementos contidos no Gráfico 1 não satisfaçam o que se entende por música, porém as práticas criativas contemporâneas já ultrapassaram muitos limites da antiga definição de música, antes circunscrita em uma afirmação em que música é somente aquilo que explicitamente apresenta harmonia, melodia e ritmo. Há mais de um século que essa definição não contempla as expressões musicais das grandes obras artísticas de tantos compositores e, ainda, há muito mais do que isso não considera as expressões artísticas de muitos povos originários.

Gráfico 1: Elementos musicais constitutivos do entimema

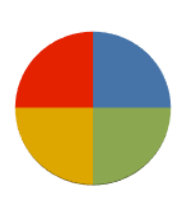

- Acentuação Rítmica

- Células Rítmicas Variadas

Fonte: Elaborada pela autora

RIAEE - Revista Ibero-Americana de Estudos em Educação, Araraquara, v. 13. n. esp. 2, p. 1436-1448, set., 2018. ISSN: $1982-5587$. 
Essa necessidade de potencializar os exercícios que envolvem a escuta traz à tona o conceito de silêncio. Heller (2008, p. 15) trata disso da seguinte maneira:

É preciso, entretanto, paciência, pois o silêncio não se deixa apreender de forma direta - faz-se necessário que se o ouça por via alusiva, lateral, de soslaio ou refletido (lembrando-nos Eurídice, resgatada do Hades por seu amado Orfeu; ele sabe-a lá, a segui-lo pelas sombras; mas, se ele se virar para olhá-la, ela se desvanece).

Uma quietude interna é premissa necessária para a escuta. Isso se educa, isso se experimenta, isso se degusta. É tal e qual sentir o perfume de algo. A princípio, pode-se apreender o que chega primeiro ao olfato, mas, com o tempo, ao se sentir o perfume outras vezes, já se pode dizer o que ocorre, por exemplo, as notas de fundo de uma fragrância; é como a boa poesia, que na primeira leitura nos captura, mas somente na segunda, terceira, na enésima, ela passa a ser parte de nós, porque representa e apresenta algo de nós nas múltiplas compreensões possíveis. Outra vez, semioses contínuas e, como tal, exige uma escuta atenta. Para Molinari (2016, p. 151), a conquista do silêncio é também disciplina, consciência e treino e conclama a Etnosonia - um neologismo criado pela autora (MOLINARI, 2016) -, como método que envolve a análise da vocalidade do discurso. Tal método, baseado em algumas premissas, aponta de maneira sintética a um instrumento de análise, a Palheta-Ouvido da Voz Ancestral do Inconsciente, baseada em um instrumento sugerido por Gelineau (2013, p. 18) denominado Palheta-Ouvido da Voz Ritual no Culto Cristão.

O nome palheta-ouvido da voz ancestral do inconsciente, apesar de incomum, aponta para assuntos comuns nos estudos interculturais, por exemplo, a ancestralidade. Como parte do plano conceitual pareceu-nos um instrumento adequado para o estudo a que nos propomos. Experimentalmente, o elemento cultural, que está inerentemente contido no discurso e que é também música, teria aqui uma possibilidade de ser exposto, uma vez que na nossa forma tradicional de conhecimento - aqui nos referimos ao registro escrito - não há condição de se fazer sonoramente com a mesma aceitação. É preciso transpor o sonoro em palavras. É preciso traduzir o entimema, ou, talvez, apresentar e representar o entimema em palavras.

Em nossa análise, os quatro elementos da palheta-ouvido da voz ancestral do inconsciente foram divididos em duas classes, elementos presentes na fala e na música e elementos presentes somente na música. O critério para essa divisão foi a questão da 
continuidade ou descontinuidade de cada um deles. Na música, excetuando-se os ad libitum - que significa livre expressão -, a continuidade é imperativa, até mesmo nas composições que dão maior liberdade ao intérprete, por exemplo, a Sequenza para Voz Solo, do compositor italiano Luciano Bério, em que o compositor indica um tempo determinado em segundos para a vocalidade do texto que, naquele contexto, é musical. Há outros exemplos, como a obra Eight Songs to a Mad King, do britânico Peter Maxwell Davies, considerada a obra pioneira do gênero músico-teatral. De qualquer modo, esse controle de tempo não encontra similitude na fala, daí a divisão entre contínuo e descontínuo.

Os quatro elementos são (MOLINARI, 2016, p. 156):

(i) da racionalidade do descontínuo das palavras - organização consciente do dizer, mais presente no discurso; (ii) da expressividade - do limiar da fala a uma fala cantada, se distribui do limiar do tom à fronteira entre uma fala cantada e um canto falado; (iii) do contínuo sonoro musical diferentes intensidades do melos na fala; (iv) da profunda expressão articulação dos silêncios de fala (em substituição ao que Gelineau aponta como a voz dos instrumentos).

Tais elementos passam, após nossa análise, a ser vistos em duas classes:

Quadro 1: Divisão em Classes dos Elementos da Palheta-Ouvido proposta por Molinari (2016)

\begin{tabular}{|l|l|}
\hline $\begin{array}{l}\text { Classe 1 - Elementos presentes na fala e na } \\
\text { música }\end{array}$ & $\begin{array}{l}\text { Classe 2 - Elementos presentes } \\
\text { somente na música }\end{array}$ \\
\hline $\begin{array}{l}\text { (i) da racionalidade do descontínuo das } \\
\text { palavras - organização consciente do dizer, mais } \\
\text { presente no discurs; }\end{array}$ & $\begin{array}{l}\text { (iii) do contínuo sonoro musical }- \\
\text { diferentes intensidades do melos na fala; } \\
\text { Melos }=\text { melodia, canto em analogia a } \\
\text { logos }=\text { discurso }\end{array}$ \\
\hline $\begin{array}{l}\text { (ii) da expressividade - do limiar da fala a uma } \\
\text { fala cantada, distribui-se do limiar do tom à } \\
\text { fronteira entre uma fala cantada e um canto falado; }\end{array}$ & \\
\hline $\begin{array}{l}\text { (iv) da profunda expressão - articulação dos } \\
\text { silêncios de fala. }\end{array}$ & \\
\hline
\end{tabular}

Fonte: Elaborada pela autora

Com essa tabela podemos dirigir nossa escuta para exemplos sonoros de discurso em que o desvelamento do entimema está em evidência. $\mathrm{O}$ entimema pode se constituir uma marca cultural. 
Quando vemos um bom imitador, quase sempre um bom humorista, reconhecemos sotaques e, quando a imitação é muito bem feita, até indicamos nome e sobrenome do imitado. O imitador, certamente, tem plena consciência dessa palheta-ouvido. Ele precisa apreender cada nuança do discurso e da musicalidade do discurso para reproduzi-lo o mais crível que puder. Na base de tudo, reside o estudo dos sons e como estes mesmos sons se transformam segundo seus locus.

Nesse ponto, a interculturalidade está em foco, se é que em algum momento esteve fora, ao menos em nossa abordagem. É nessa borda, nesse lugar de fronteira, que a complexidade reside e é dela que emergem novos caminhos. Um dos principais referenciais para essa relação com as bordas, com as fronteiras entre áreas de conhecimento, é a proposta de Schafer (2011a; 2011b), que aponta lacunas e possíveis condutas para experiências necessárias no campo de estudo que vimos tratando. Nas palavras do autor:

Um estudo intercultural a respeito da relação existente entre expressão musical e percepção auditiva nunca foi realizado, mas não deve ser adiado por muito tempo. Seria de grande valia responder a perguntas como estas: De que modo uma sociedade vê a relação entre frequência, tempo e intensidade? Entre continuidade e interrupção? Entre sons de impacto e sons em estado estacionário? Entre figura e fundo? Sinal e ruído? Ou ruído e silêncio - o que quer dizer dinamismo e repouso? (SCHAFER, 2011a, p. 219).

O autor convida-nos a uma ação imediata e isso era ainda no final do século passado. Ainda hoje constatamos que há muito a ser feito, logicamente. Não era difícil prever que um campo de estudo tão amplo levaria tanto tempo para se consolidar. Assim, com Schafer (2011a; 2011b), buscamos caminhos mais propícios para nossas ações.

O estudo de Schafer (2011a; 2011b) constitui-se em um importante condensador de saberes multidisciplinares e um guia indispensável para novas pesquisas na área, daí a relevância desse referencial para o nosso estudo, que acomoda e sustenta todas as demais afirmativas, anteriormente explicitadas. As práticas interculturais, nessa perspectiva, ocorrem na dinâmica necessária para o equilíbrio das relações e das diferenças entre os variados campos de conhecimento. O termo intercultural amplia-se para as relações entre áreas de conhecimento, não somente entre povos ou nações. O conceito de base que define a inter-relação é disparador para o foco nas relações próprias da dinâmica cultural dos diversos métiers. Nessa dinâmica, surgem as inovações pedagógicas. 


\section{Inovação pedagógica}

O termo inovação pedagógica, como tantos outros durante períodos específicos de tempo, tem sido utilizado nas pesquisas em educação, mas ainda assim não se deve tomá-lo como análogo à inovação tecnológica. No caso da inovação pedagógica, o foco dirige-se para ações bem-sucedidas em contextos específicos de educação e que se caracterizam como inovação, porque rompem, de alguma forma, a cotidiana aplicação de métodos e técnicas de ensino.

Para Fino (2008, p. 05), “O caminho da inovação raramente passa pelo consenso ou pelo senso comum, mas por saltos premeditados e absolutamente assumidos em direção ao, muitas vezes, inesperado. Aliás, se a inovação não fosse heterodoxa, não seria inovação".

Nesse sentido, a amplitude do que se pode considerar como inovação pedagógica toma grandes proporções e o centro de atenção está em propiciar mudanças qualitativas para uma boa educação. Ajuda-nos pensar sobre o assunto olhando para o que é e para o que não é inovação pedagógica. Para tal, apresentamos no Quadro 2 a definição de Fino (2008).

Quadro 2: Inovação pedagógica na definição de Fino (2008)

\begin{tabular}{|l|l|}
\hline \multicolumn{1}{|c|}{ Inovação Pedagógica É: } & \multicolumn{1}{|c|}{ Inovação Pedagógica NÃO É: } \\
\hline $\begin{array}{l}\text { 1. A inovação pedagógica, ainda que inspirada por } \\
\text { ideias ou movimentos que extravasam do âmbito } \\
\text { local, é sempre uma opção individual e local; }\end{array}$ & $\begin{array}{l}\text { 1. A inovação pedagógica não é o } \\
\text { resultado da formação de professores, } \\
\text { ainda que a (boa) formação seja } \\
\text { determinante; }\end{array}$ \\
\hline $\begin{array}{l}\text { 2. A inovação pedagógica dentro da escola envolve } \\
\text { sempre o risco de esbarrar contra o currículo. }\end{array}$ & $\begin{array}{l}\text { 2. A inovação pedagógica não é } \\
\text { induzida de fora, mas um processo de } \\
\text { dentro, que implica reflexão, } \\
\text { criatividade, sentido crítico e } \\
\text { autocrítico; }\end{array}$ \\
\hline
\end{tabular}

Fonte: Elaborada pela autora

Valendo-nos das afirmações do Quadro 2, passamos a olhar para quais ações inovadoras poderíamos suscitar nos cursos de formação de professores em andamento no nosso campus universitário, situado no Brasil, no interior do estado do Maranhão. Para isso, tomamos a oportunidade do Programa Institucional de Bolsas de Iniciação Científica (Pibic) com apoio da Fundação de Amparo à Pesquisa do Estado do Maranhão (Fapema) e da própria universidade, a Universidade Federal do Maranhão (UFMA), e começamos uma sensibilização para a escuta envolvendo três planos de trabalho de bolsistas de um curso de 
licenciatura em Linguagens e Códigos - Música, por sua vez ligado a um grupo de pesquisa, também oficial, cadastrado no diretório dos grupos de pesquisa do Conselho Nacional de Desenvolvimento Científico e Tecnológico (CNPQ), o Grupo de Pesquisa Performance e Pedagogia Wolfsohn-Molinari.

O fato de haver uma junção de pesquisadores envolvidos no grupo de pesquisa também possibilitou a partilha de conhecimentos entre os estudantes do doutorado em Humanidades e Artes com Ênfase em Ciências da Educação da Universidade Nacional de Rosário - Argentina, dando suporte aos encontros presenciais e virtuais do grupo, promovendo vários níveis de reflexão sobre o assunto. Finalmente, a ação também se constitui como parte de um projeto de pós-doutorado em andamento na Universidade Estadual Paulista (Unesp).

$\mathrm{Na}$ busca de responder o que poderíamos fazer de forma a demarcar a inovação pedagógica e qual seria o plano conceitual, voltamos nosso olhar para o entroncamento resultante do fazer na criação artística, na performance musical e na educação musical, e, dados os primeiros estudos com o Grupo de Estudos Compor e Educar, com o qual também temos relações estabelecidas, entendemos que os métodos e procedimentos que usamos em cada um de nossos fazeres musicais são potencialmente inovadores quando vistos como o próprio método.

Tanto a performance musical quanto a criação artística e a educação musical têm procedimentos muito bem determinados, por exemplo, a repetição seguida de autoavaliação e de reelaboração, a reinvenção do mesmo, como na improvisação, a organização dos elementos mais e menos expressivos, a escolha do que permanece e o que se descarta no momento, e o mais significativo é que as pedagogias ativas, notadamente as do século XX, com especial destaque para a proposta de Schafer (2011a; 2011b), na qual o centro de tudo é o desenvolvimento do estudante, visando uma escuta ativa, fizeram emergir a possibilidade de, por meio da sensibilização da escuta, conectar interculturalidade e inovação pedagógica.

A inovação é demarcada por um fazer musical em que o elemento sonoro serve de base para a construção de habilidades, a princípio desejadas na formação musical, mas, segundo o que o nosso plano conceitual apresentou, verdadeiramente passíveis de promover um desenvolvimento mais amplo, no âmbito das licenciaturas como um todo.

Levamos nosso primeiro plano para discussão num evento acadêmico na cidade de Alcântara - Maranhão, o III Simpósio Nacional de Arte e Mídia, e nos debates promovidos 
notamos que os educadores envolvidos, apesar de não terem histórico anterior de trabalho com a música nessa perspectiva, mostraram-se interessados. Para nós, foram surpreendentes a disposição e o interesse em conhecer mais sobre o assunto.

Nosso próximo passo é a construção do conjunto de condutas a serem estabelecidas, bem como o registro das atividades. Neste artigo, detivemo-nos em demarcar o plano conceitual sem, no entanto, explicitar como a ação ocorre baseada nesse mesmo plano, por se tratar de um dossiê em que apresentamos nossa posição teórica ao articular fazeres com o OIIIIPE.

\section{Considerações finais}

Tendo em vista o objetivo de descrever o plano conceitual que norteou o planejamento das ações a serem desenvolvidas num curso de formação de professores, com este estudo foi possível:

I. delimitar o marco conceitual, a saber, o proposto por Schafer (2011a; 2011b) em seus estudos, como elemento integrador entre a interculturalidade, as pedagogias ativas e o som;

II. a perspectiva de compreensão da escuta, abarcando a semiótica russa em Lotman (1978; 1996) e Lotman e Uspenskii (1981) e, de maneira correlata, a Pedagogia Wolfsohn-Molinari, por meio da Etnosonia em Molinari (2016);

III. a detecção da ausência de um plano de aplicação perante o plano conceitual, que deverá, portanto, ser constituído como fruto deste estudo; e

IV. o registro e a publicação dos resultados da aplicação supracitada visando à promoção da interculturalidade e da inovação pedagógica.

Seguindo a metodologia de suporte, mais que uma análise sobre o processo, sucedeu um aprofundamento deste, para abrir um espaço, possivelmente novo, de conduta sobre um fazer que anteriormente, mesmo que proposto nos mesmos moldes, dirigia-se a lugares de experimentação diferentes, ainda que complementares.

\section{REFERÊNCIAS}

RIAEE - Revista Ibero-Americana de Estudos em Educação, Araraquara, v. 13. n. esp. 2, p. 1436-1448, set., 2018. ISSN: 1982-5587. 
FINO, Carlos Nogueira. Inovação pedagógica: significado e campo (de investigação). In: MENDONÇA, Alice.; BENTO, António V. (Org.). Educação em tempo de mudança. Funchal: Grafimadeira, 2008. p. 277-287.

GELINEAU, Joseph. Os cantos da missa no seu enraizamento ritual. São Paulo: Paulus, 2013.

HELLER, Alberto Andrés. John Cage e a poética do silêncio. 2008. Tese (Doutorado em Teoria Literária) - Centro de Comunicação e Expressão, Universidade Federal de Santa Catarina, Florianópolis.

LOTMAN, Iúri. A estrutura do texto artístico. Lisboa: Estampa, 1978.

LOTMAN, Iúri. La semiosfera I: semiótica de la cultura y del texto. Valencia: Frónesis Cátedra, 1996.

LOTMAN, Iúri.; USPENSKII, Boris Aleksandrovich. Sobre o mecanismo semiótico da cultura, em Lotman, I. Ensaios de semiótica soviética. Lisboa: Horizonte, 1981.

MOLINARI, Paula. Memoir about pedagogic formation. Thoiras: Cairh, 2008.

MOLINARI, Paula. Alfred Wolfsohn na obra de Charlotte Salomon: uma cartografia que emerge da voz. 2014a. Tese (Doutorado em Comunicação e Semiótica) - Pontifícia Universidade Católica de São Paulo, São Paulo.

MOLINARI, Paula. Pedagogia Wolfsohn-Molinari para o ensino da música. Anais do IX Encontro Regional Sudeste da ABEM, Vitória, ES, 2014b. Disponível em:

<http://www.abemeducacaomusical.org.br>. Acesso em: 23 jul. 2015.

MOLINARI, Paula. Etnosonia: em busca do método. In: MOLINARI, Paula. (Org.).

Música, educação e cultura: tecituras e tessituras no nordeste brasileiro. Campo Limpo Paulista: FACCAMP, 2016. p. 141-163. Disponível em:

<https://itunes.apple.com/WebObjects/MZStore.woa/wa/viewBook?id=1262963052>.

Acesso em: 10 fev. 2018.

SCHAFER, R. Murray. A afinação do mundo: uma exploração pioneira pela história passada e pelo atual estado do mais negligenciado aspecto do nosso ambiente: a paisagem sonora. Tradução de Marisa T. Fonterrada. 2. ed. São Paulo: Unesp, 2011 a.

SCHAFER, R. Murray. O ouvido pensante. Tradução de Marisa Trench de O. Fonterrada, Magda R. Gomes da Silva e Maria Lúcia Pascoal. 2. ed. São Paulo: Unesp, 2011 b.

SITE EDUCAÇÃO CC. Conteúdos Educacionais e Educação Sistemática. Disponível em: <http://www.educacao.cc/lingua-portuguesa/diferenca-entre-ouvir-e-escutar-entendere-compreender/>. Acesso em: 23 fev. 2018. 


\section{Como referenciar este artigo}

MOLINARI, Paula. A pedagogia da escuta: aproximações entre interculturalidade e inovação pedagógicaia. Revista Ibero-Americana de Estudos em Educação, Araraquara, v. 13. n. esp. 2, p. 1436-1448, set., 2018. ISSN: 1982-5587. DOI: 10.21723/riaee.v13.nesp2.set2018.11653

Submetido em: 15/02/2018

Aprovado em: 03/05/2018 